\title{
Apoptotic and chemotherapeutic properties of iron(III)-salophene in an ovarian cancer animal model
}

\author{
Thilo S Lange ${ }^{1,2}$ \\ Carolyn McCourt ${ }^{2}$ \\ Rakesh K Singh ${ }^{2}$ \\ Kyu Kwang Kim² \\ Ajay P Singh ${ }^{3}$ \\ Brian S Luisi ${ }^{4}$ \\ Onur Alptürk ${ }^{5}$ \\ Robert M Strongin 6 \\ Laurent Brard ${ }^{2}$ \\ 'Division of Biology and Medicine \\ Brown University, Providence, \\ RI, USA; ${ }^{2}$ Molecular Therapeutics \\ Laboratory, Program in Women's \\ Oncology, Department of Obstetrics \\ and Gynecology, Women and \\ Infants' Hospital of RI, Warren \\ Alpert Medical School of Brown \\ University, Providence, RI, USA; \\ ${ }^{3}$ Department of Plant Biology, Rutgers \\ University, New Brunswick, NJ, USA; \\ ${ }^{4}$ Department of Chemistry, Brown \\ University, Providence, RI, USA; \\ ${ }^{5}$ Department of Medicine, University \\ of Pittsburgh School of Medicine, \\ Pittsburgh, PA, USA; ${ }^{6}$ Department \\ of Chemistry, Portland State \\ University, Portland, OR, USA
}

\begin{abstract}
The cytotoxicity of organometallic compounds iron(III)-, cobalt(III)-, manganese(II)-, and copper(II)-salophene (-SP) on platinum-resistant ovarian cancer cell lines was compared. Fe-SP displayed selective cytotoxicity $\left(\mathrm{IC}_{50}\right.$ at $\sim 1 \mu \mathrm{M}$ ) against SKOV-3 and OVCAR-3 cell lines while Co-SP caused cytotoxic effects only at higher concentrations $\left(\mathrm{IC}_{50}\right.$ at $\left.60 \mu \mathrm{M}\right)$ and $\mathrm{Cu}$-SP effects were negligible. High cytotoxicity of Mn-SP $(30-60 \mu \mathrm{M})$ appeared to be nonspecific because the Mn-chloride salt reduced cell viability similarly. The effect of Fe-SP at $1 \mu \mathrm{M}$ proved to be ovarian cancer cell selective when compared to a panel of cell lines derived from different tumors. The first irreversible step in the induction of cell death by Fe-SP occurred after $3 \mathrm{hrs}$ as indicated by the mitochondrial transmembrane potential $(\Delta \Psi \mathrm{m})$ and was mainly linked to apoptotic, not necrotic events. To evaluate the toxicity of Fe-SP in vivo we conducted an acute toxicity study in rats. The $\mathrm{LD}_{50}$ of Fe-SP is $>2000 \mathrm{mg} / \mathrm{kg}$ orally and $>5.5 \mathrm{mg} / \mathrm{kg}$ body weight by intraperitoneal injection. An ovarian cancer animal model showed that the chemotherapeutic relevant dose of Fe-SP in rats is $0.5-1 \mathrm{mg} / \mathrm{kg}$ body weight. The present report suggests that $\mathrm{Fe}-\mathrm{SP}$ is a potential therapeutic drug to treat ovarian cancer.
\end{abstract}

Keywords: iron(III)-salophene, chemotherapeutic properties, p38 MAPK, ovarian cancer animal model

\section{Introduction}

The current treatment of a variety of tumors, including ovarian cancer, relies on organometallic platinum compounds. In 2007, ovarian cancer was the leading cause of death $(15,280$ cases $)$ from gynecologic malignancies and ranks second $(22,430)$ among newly diagnosed gynecological cancers in the United States. ${ }^{1,2}$ Although most patients $(70 \%-80 \%)$ initially respond to cytoreductive surgery and adjuvant paclitaxel and platinum-based chemotherapy, the majority will experience disease recurrence. ${ }^{3-5}$ While re-treatment with a platinum-based drug is possible for some women, the response rate to current second or third line chemotherapy is below 33\% mainly due to drug resistance. ${ }^{6-8}$ The mechanism of platinum resistance appears to include decreased cellular uptake, increased efflux, improved DNA repair, and prevention of DNA cross-linking. ${ }^{9,10}$ Likely candidates for platinum alternatives fall into the category of metal compounds. ${ }^{8,11,12}$

The design of new metal-based drugs is often challenged by physiochemical properties and ultimately their specific effects in vivo. One approach to control the cytotoxic responses of metal-based compounds is to engage biologically essential transition metals, such as iron (Fe), manganese $(\mathrm{Mn})$, copper $(\mathrm{Cu})$, or cobalt (Co). ${ }^{11-13}$ In a recent study, we suggested that organometallic compound iron(III)-salophene (Fe-SP) displays properties that may assist in the treatment of ovarian cancer. ${ }^{14}$ Salophenes represent a class of organic compounds defined 
by two Schiff's bases connecting three aromatic moieties that offer potent binding with transition metals and are closely related to salens which also contain Schiff's bases that are constituted of aliphatic diamines. In our previous study Fe-SP displayed cytotoxic activity against ovarian adenocarcinoma cell lines at concentrations which did not affect primary fibroblasts $(0.1-1 \mu \mathrm{M}) .{ }^{14}$ In addition, treatment with Fe-SP revealed morphological hallmarks of apoptosis and chromatin fragmentation in SKOV-3 cells, caused activation of markers of apoptosis and arrest of cell cycle progression in S-phase. ${ }^{14}$ Furthermore, Fe-SP did not show systemic toxicity in mice at concentrations that in the present manuscript are shown to be chemotherapeutic relevant doses in a rat ovarian cancer cell model. ${ }^{14}$ Based on our studies a patent was filed. This invention comprises the synthesis, biological applications, and pharmaceutical compositions of metal-salophenes (MSPs) and their use as therapeutic anti-neoplastic, anti-angiogenic and anti-cancer drugs.

The objective of the present study was to compare the cytotoxicity of Fe(III) vs cobalt(III), manganese (II), or copper (II) as chloride-salts or when complexed with SP on ovarian cancer cell lines. We compared the cytotoxic effect of Fe-SP on ovarian cancer cells to a panel of cell lines derived from other solid tumors. An evaluation of the events leading to cell death was conducted by performing a mitochondrial membrane depolarization assay, a dose/time-dependent study of the kinetics of cytotoxic action by Fe-SP, by analysis via FACS of necrotic vs apoptotic events and of activation of apoptotic markers in vivo (rat model; IP treatment with Fe-SP). An acute toxicity study is presented along with an efficacy study of Fe$\mathrm{SP}$ in a rat ovarian cancer cell model. The present report suggests that the novel organometallic compound Fe-SP induces ovarian cancer cell death by apoptosis in vitro and in vivo and at sub-toxic concentrations displays properties as a potential therapeutic drug in the treatment of ovarian cancer.

\section{Materials and methods Synthesis of salophene}

The synthesis of the salophene ligand (SP, Figure 1A) followed a previously reported procedure. ${ }^{14,15}$ 1,2-phenylenediamine ( $1.24 \mathrm{~g}, 11.5 \mathrm{mmol})$ was added to a solution of $o$-vanillin $(3.5 \mathrm{~g}, 23 \mathrm{mmol})$ in anhydrous ethanol $(20 \mathrm{~mL})$ and the yellowish solution stirred and refluxed for $2 \mathrm{~h}$. The reddish suspension was filtered and re-crystallized with boiling ethanol and the resultant reddish needles collected and dried (2.8 g SP, 65\% yield). Salophene complexes were prepared as follows: SP $(1.46 \mathrm{mmol})$ dissolved in acetone $(44 \mathrm{~mL})$ was carefully combined with $1.46 \mathrm{mmol}$ of the respective chloride salts $\left(\mathrm{FeCl}_{3}, \mathrm{CuCl}_{2}, \mathrm{Cl}_{3} \mathrm{CoH}_{18} \mathrm{~N}_{6}, \mathrm{MnCl}_{2}\right)$ dissolved in acetone $(5.5 \mathrm{~mL})$. The resultant microcrystalline solids that grew in solution were filtered, washed thoroughly with acetone, and dried to obtain the Me-SP complex which were dissolved in DMSO (dimethyl sulfoxide) for experiments in tissue culture and characterized by HPLC and X-ray crystallography ${ }^{14}$ with a high resolution X-ray diffraction system (Bruker SMART diffractometer using SHELXTL-97 software; Bruker AXS Inc., Madison, WI).

\section{Cell culture}

Human cell lines SKOV-3 (ovarian adenocarcinoma), OVCAR-3 (ovarian epithelial adenocarcinoma), CaOV-3 (ovarian adenocarcinoma), A-431 (epidermoid skin carcinoma), PC-3 (prostate adenocarcinoma), LNCaP (prostate carcinoma), and BxPC-3 (pancreatic adenocarcinoma SH-SY5Y (neuroblastoma) were obtained from American Type Culture Collection (Manassas, VA). Cells were grown T75 cell culture flasks (Corning, New York, NY) in complete medium (Gibco, Rockville, MD) according to the suppliers recommendation. NUTU-19 rat epithelial ovarian cancer cells, a gift from Dr G. Scott Rose (Section of Gynecologic Oncology, Cleveland Clinic Foundation, Cleveland, OH) were cultured in RPMI 1640 supplemented with $10 \%$ fetal bovine serum, $100 \mathrm{U} / \mathrm{mL}$ penicillin, and $100 \mu \mathrm{g} / \mathrm{mL}$ streptomycin. NUTU-19 cell line was derived from Fischer 344 rats. ${ }^{16}$

\section{Cell viability assay}

Viability of cells before and after drug treatment was determined was determined by the $96^{\circledR}$ Aqueous-One-Solution Assay (Promega, Madison, WI). The test was carried out as described previously. ${ }^{17}$ This colorimetric assay is based on the ability of mitochondria to reduce a substrate [MTS, 3-(4,5-dimethylthiazol-2-yl)-5-(3-carboxymethoxyphenyl)2-(4-sulfophenyl)-2H-tetrazolium] into a soluble formazan product quantified by measuring the absorbance at $490 \mathrm{~nm}$. The resulting OD is directly proportional to the number of living cells. ${ }^{18}$ Briefly, cells $\left(5 \times 10^{3} /\right.$ well $)$ were plated into 96 well flat bottom plates (Corning, Inc., Corning, NY) before treatment with various drugs or vehicle (DMSO) as indicated. Following incubation at $37^{\circ} \mathrm{C}$ in a cell culture incubator for $20 \mathrm{~h}$ MTS reagent was added at a 1:10 dilution to the medium. The samples were incubated for an additional $4 \mathrm{~h}$ before absorbance was measured at $490 \mathrm{~nm}$ in an ELISA plate reader (Thermo Labsystems, Waltham, MA). Experiments were performed in triplicates; data are expressed as the mean 
of the triplicate determinations $(\mathrm{X} \pm \mathrm{SD})$ of a representative experiment in $\%$ of absorbance by samples with untreated cells $(=100 \%)$.

\section{Mitochondrial transmembrane potential analysis}

Cells $\left(1 \times 10^{6}\right)$ were seeded in a $100 \mathrm{~mm}$ petri-dish and treated with $1 \mu \mathrm{M}$ of Fe-SP or SP for $3 \mathrm{~h}$. After treatment the cells were washed with phosphate-buffer solution (PBS), resuspended in fresh medium $\left(5 \times 10^{5}\right.$ cells $\left./ \mathrm{mL}\right)$ and incubated with $15 \mathrm{nM} \mathrm{3,3'-dioctadecyloxa-carbocyanine} \mathrm{perchlorate}$ (DiOC18(3); Invitrogen Eugene OR) for $30 \mathrm{~min}$ at $37^{\circ} \mathrm{C}$. The cells were washed twice with DPBS and measured by flow cytometry (excitation, $488 \mathrm{~nm}$; emission, $520 \mathrm{~nm}$ ). Data was acquired on a BD FACSort flow cytometer using CellQuest software (BD Immunocytometry-Systems, San Jose, CA) and analyzed (ModFit LT software, Verity Softwarehouse, Inc., Topsham, ME). Ten thousand cells were analyzed for each sample.

\section{Determination of apoptotic and necrotic cells (by FACS)}

The quantification of apoptotic cells was determined by combination staining with Annexin V and 7-Aminoactinomycin (Apoptosis detection kit; BD Biosciences, San Jose, CA) allowing discrimination between early apoptotic cells (Annexin V positive), late apoptotic cells (Annexin $\mathrm{V}$ and 7-AAD positive), and necrotic cell death (7-AAD positive). Cells were seeded into $100 \mathrm{~mm}^{2}$ tissue culture dishes $\left(5 \times 10^{5}\right.$ cells/dish), treated (result section), floating and attached cells combined, washed once with PBS, $\mathrm{pH} 7.4$, $(250 \times \mathrm{g}, 5 \mathrm{~min})$ and stained. Analysis followed immediately on a Becton Dickinson (San Jose, CA) FACSCalibur; ten thousand events were analyzed for each sample, and gating was used to select the appropriate population of cells.

\section{Animal toxicity study}

Animal experiments were carried out in the animal facilities of Rhode Island Hospital (RIH), RI, USA with strict adherence to the guidelines of the Animal Welfare Committee of RIH and Women and Infants Hospital.

The toxicity of Fe-SP in vivo was evaluated in rats (adult pathogen-free Fischer 344 female rats, weight, 100-150 g; Taconic, Germantown, NY) in a trial study following the " $\mathrm{Up}$ and Down Method" with Fe-SP applied by intra-peritoneal (IP) injection and by PO (oral gavage). The study was performed in compliance with OECD guideline 425 (see http://www.oecd.org/dataoecd/17/51/1948378.pdf; testing of chemicals, section 4: Health Effects Test No. 425). The objective of this study was to assess the acute toxicity of Fe-SP when administered in a single dose to rats intraperitoneally and orally at a defined dose. Animals were randomly assigned to experimental groups (IP and PO groups, 7 in each group) and maintained at a temperature of $22 \pm 1{ }^{\circ} \mathrm{C}$ and a relative humidity of $55 \% \pm 5 \%$, with a $12 \mathrm{~h}$ light/dark cycle.

The amount of Fe-SP administered ranged from $55-2000 \mathrm{mg} / \mathrm{kg}$ in the PO group and $5.5-17 \mathrm{mg} / \mathrm{kg}$ in the IP group. DMSO/PBS $(20 / 80 \mathrm{v} / \mathrm{v})$ stocks of Fe-SP were diluted 100 -fold prior to administration to allow a constant dosage volume. Rats were administered Fe-SP by $\mathrm{PO}$. The rats were fasted overnight prior to dosing and returned to feeding $3 \mathrm{~h}$ after dosing. On the day of dosing, all the animals were observed for signs of intoxication at $30 \mathrm{~min}$ to $4 \mathrm{~h}$ following dosing and were observed twice a day for 14 days. Body weights of rats were individually recorded before dosing and at weekly intervals thereafter. All animals were sacrificed at the end of the observation period.

\section{Animal (Rat) ovarian cancer model}

Twenty rats in this therapeutic trial were divided into two treatment groups $(0.5$ or $1.0 \mathrm{mg} \mathrm{Fe}-\mathrm{SP} / \mathrm{kg}$ ) of five animals each and one control group (10 animals). Briefly, NUTU-19 cells were cultured to $80 \%$ confluence, harvested, counted for cell number and viability, and injected intra-peritoneal (IP) $\left(1 \times 10^{6}\right.$ cells in PBS $)$. In this model, $100 \%$ of animals develop disease after three weeks. After three weeks daily intra-peritoneal injections of Fe-SP were administered at 0.5 and $1 \mathrm{mg} / \mathrm{kg}$ body weight. Vehicle (DMSO/PBS, $20 / 80 \mathrm{v} / \mathrm{v}$ ) was administered to the untreated control group. Animals were inspected daily for clinical condition and discomfort and pain per IACUC protocols. Food consumption and body weights were be recorded weekly. All twenty animals were euthanized at the fifth week and tumor tissue was harvested.

\section{Western blotting of tissue samples}

Tumor tissue from all animals in a treatment group was collected and pooled, then weighed and diced into very small pieces using a clean razor blade. Three $\mathrm{mL}$ of ice cold lysis buffer (1\% NP-40, $20 \mathrm{mM}$ Tris pH 8.0, $137 \mathrm{mM}$ $\mathrm{NaCl}, 10 \%$ glycerol, $2 \mathrm{mM}$ EDTA, $1 \mathrm{mM}$ activated sodium orthovanadate, $10 \mu \mathrm{g} / \mathrm{mL}$ Aprotinin, $10 \mu \mathrm{g} / \mathrm{mL}$ Leupeptin, Inhibitor Cocktail P-2714; Sigma-Aldrich, St. Louis, MO) were used per gram of tissue that was homogenized using 
a sonicator (Sonic Dismembrator 100; Fisher Scientific, Pittsburgh, PA; 4 watts output power, setting 10; 30 cycles of $5 \mathrm{sec}$ each) while maintaining the samples on ice. The suspension was centrifuged at $10,000 \mathrm{~g}$ for $1 \mathrm{~min}$ at $4{ }^{\circ} \mathrm{C}$ and centrifugation of the supernatant repeated twice. The protein concentration of the remaining supernatant of the cell lysate was quantitated (BioRad protein estimation kit, Hercules, CA) and Western blotting was carried out as described previously ${ }^{17}$ and summarized here: samples were boiled in the presence of 5X SDS-PAGE sample buffer and $50 \mu \mathrm{g}$ total cellular protein/lane were separated on $12 \%$ SDS-polyacrylamide gels and blotted onto PVDF membranes. The blots were blocked with 5\% nonfat dry milk in PBST for $1 \mathrm{hr}$ at room temperature and incubated overnight at $4{ }^{\circ} \mathrm{C}$ with the antibodies against Caspase-3 \#9662 or cleaved PARP-1 \#9541 (Cell Signaling Technology, Beverly, MA) at a 1:1000 dilution in 5\% BSA in PBST on a rotating platform. After washing in PBST the blots were incubated with secondary antibody (peroxidase-conjugated antibodies; Amersham-Pharmacia Biotech, Piscataway, NJ). The bands were visualized using horseradish peroxidase-conjugated secondary antibodies (Amersham-Pharmacia Biotech, Piscataway, NJ) and documented by autoradiography $(\mathrm{F}-\mathrm{B} \times 810$ Film, Phenix, Hayward, CA).

\section{Statistical analyses}

Means \pm standard deviations (SD) were calculated. For animal experiments, mean hemorrhagic ascites volume and omental weight were compared between groups by ANOVA with Scheffe's adjustment for multiple comparisons. Software used for these analyses was STATA version 9.0 (Statacorp, College Station, TX).

\section{Results}

\section{Specific cytotoxic effect of iron-salophene on human platinum-resistant ovarian cancer cell lines}

In an initial approach to analyze the cytotoxic effects of various metal-salophene complexes on ovarian cancer cells we performed a viability assay employing SKOV-3 and OVCAR-3 ovarian cancer cell lines. The cells were treated for $24 \mathrm{~h}$ with various concentrations $(0.1-60 \mu \mathrm{M})$ of either complexed salophene (Fe(III)-SP, Co(III)-SP Cu(II)-SP, $\mathrm{Mn}(\mathrm{II})-\mathrm{SP})$ or the respective metal chloride salts alone $\left(\mathrm{Fe}^{3+}, \mathrm{Co}^{3+}, \mathrm{Cu}^{2+}, \mathrm{Mn}^{2+}\right)$. Treatment with noncomplexed salophene (SP), which did not significantly affect cell viability even at concentrations of $60 \mu \mathrm{M}$ served as a negative control.
Among these compounds only Fe-SP proved to be highly cytotoxic to SKOV-3 and OVCAR-3 cells $\left(\mathrm{IC}_{50} \sim 1 \mu \mathrm{M}\right)$ after $24 \mathrm{~h}$ of treatment (Figure $1 \mathrm{~B}$ ). In contrast, $\mathrm{Cu}-\mathrm{SP}$ did not significantly reduce cell viability even at concentrations as high as $60 \mu \mathrm{M}$. Co-SP exerted specific but only mildly cytotoxic effects on both cell lines tested $\left(\mathrm{IC}_{50}=60 \mu \mathrm{M}\right)$ when compared to either noncomplexed salophene or the respective Co-chloride salt alone. A relatively high cytotoxcicity of $\mathrm{Mn}-\mathrm{SP}$ at concentrations of 30-60 $\mu \mathrm{M}$ was observed which, however, appeared to be unspecific and solely linked to the presence of the Mn-ion since the Mn-chloride salt alone reduced cell viability almost identically to complexed Mn-SP.

We compared the cytotoxcicity of Fe-SP on ovarian cancer cell lines to the effect on the viability of other human cancer cell lines such as A-431 (epidermoid skin carcinoma), PC-3 (prostate adenocarcinoma), LNCaP (prostate carcinoma), BxPC-3 (pancreatic adenocarcinoma), or SH-SY5Y (neuroblastoma) alongside with a third ovarian cancer cell line (CaOV-3, ovarian adenocarcinoma) (Figure 2). At concentrations above $3 \mu \mathrm{M}$ Fe-SP was lethal to all cell lines other than the neuroblastoma cell line tested $\left(\mathrm{IC}_{50}=3 \mu \mathrm{M}\right)$. However, the cytotoxic effect of Fe-SP at $1 \mu \mathrm{M}\left(\mathrm{IC}_{50}\right.$ for OC cells) was significantly lower for all nonovarian cancer cell lines as compared to platinum-resistant SKOV-3, OVCAR-3 and $\mathrm{CaOV}-3$ ovarian cancer cells. Noncomplexed salophene at $3 \mu \mathrm{M}$ did not reduce the viability of any cell line treated (Figure 2, right panel).

\section{Kinetics of the cytotoxic effects of Fe-SP; mitochondrial membrane depolarization, necrotic- and apoptotic population of SKOV-3 after Fe-SP treatment}

Kinetic analysis of the viability of platinum-resistant SKOV-3 cells revealed that the effect of Fe-SP treatment follows a dose- and time-dependent pattern (Figure 3 ). High cytotoxicity could be observed for treatment at 5 and $10 \mu \mathrm{M} \mathrm{Fe-SP}$ within six hours reaching maximum responses within $12 \mathrm{~h}$ of treatment. At a Fe-SP concentration which selectively affects different cell lines $(1 \mu \mathrm{M})$ (Figure 2$)^{14}$ the response of SKOV-3 ovarian cancer cells needed $24-48$ h to unfold (Figure 3).

In a first approach to understand the effect of Fe-SP on cellular functions we analyzed the integrity/loss of the mitochondrial transmembrane depolarization potential $(\Delta \Psi \mathrm{m})$ as determined by fluorescent staining with DiOC18(3) followed by FACS analysis (Figure 4A). Treatment of SKOV-3 ovarian cancer cells with the cell-selective concentration of $1 \mu \mathrm{M}$ 


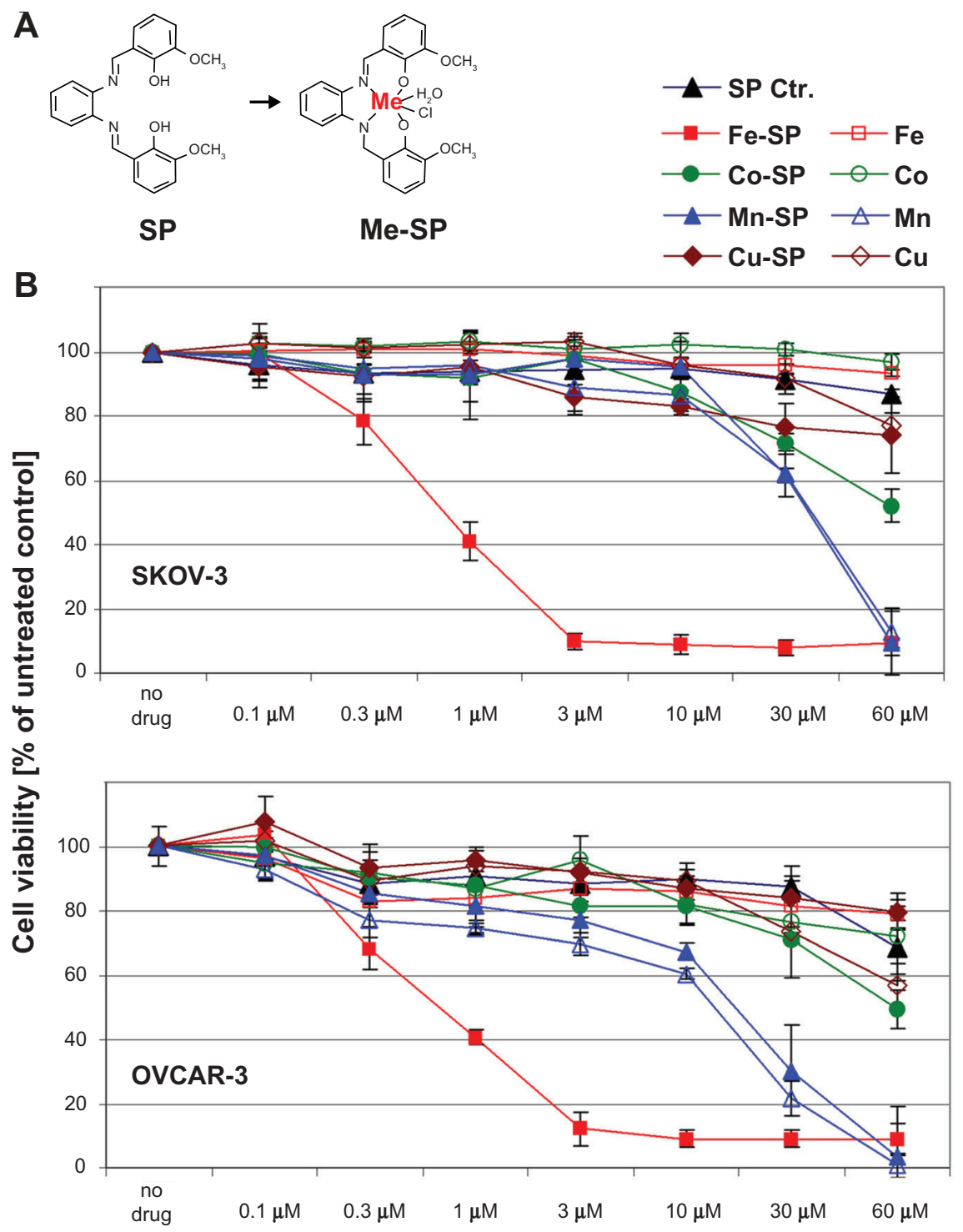

Figure I Comparative analysis of the cytotoxic effect of various metallo-salophenes on platinum resistant ovarian cancer cell lines. (A) Structure of salophene ligand (SP) and metal-salophene complex (Me-SP). (B) Human ovarian cancer cells (SKOV-3, OVCAR-3) were treated for $24 \mathrm{~h}$ with various concentrations $(0.1-60 \mu M)$ of either newly synthesized transition metal salophene complexes (Fe(III)-SP, Co(III)-SP, Mn(II)-SP, and Cu(II)-SP) or the respective metal chloride alone $\left(\mathrm{Fe}^{3^{+}}, \mathrm{Co}^{3^{+}}, \mathrm{Mn}^{2+}, \mathrm{Cu}^{2+}\right)$ or the noncomplexed parent compound (SP). The MTS viability assay was carried out as described (Materials and methods). Experiments were performed in triplicates; data are expressed as the mean of the triplicate determinations $(X \pm S D)$ of a representative experiment in\%cell viability of untreated cells $(100 \%)$.

Fe-SP resulted in a time-dependent increase in the number of cells with $\Delta \Psi \mathrm{m}$. Fluorescent staining with DiOC18(3) after Fe-SP treatment for $3 \mathrm{~h}$, in contrast to nontreated or SP treated controls, revealed two populations of cells (two peaks in the FACS profile; Figure 4A, right panel). Fe-SP treatment led to a loss of the integrity of the $\Psi \mathrm{m}$ in $40 \%$ of the population as compared to untreated cells $(7.9 \%)$ or cells treated with parent compound SP $(9.4 \%)$.

To determine the percentage of apoptotic versus necrotic cells after Fe-SP treatment FACS analysis was carried out. SKOV-3 cells were treated with $1 \mu \mathrm{M}$ Fe-SP or noncomplexed SP for $24 \mathrm{~h}$ and floating and attached cells collected and combined. The quantification of apoptotic cells was determined by staining with Annexin $V$ and of necrotic cells by 7-AAD staining (see material and methods). Combination staining with both markers allowed discrimination between early apoptotic cells (Annexin V positive), late apoptotic cells (Annexin V and 7-AAD positive), and necrotic cell death (7-AAD positive). The assay revealed an apoptotic subpopulation of $77.8 \%$ (as determined by the combination of cells both in early and late apoptosis, Q4 + Q2; Figure 4B) for Fe-SP treated cells. In contrast only $10.8 \%$ of SP treated cells and $1.5 \%$ of nontreated cells underwent apoptosis. Necrosis was observed for 19.1\% (Q1 + Q2; Figure 4B) of 


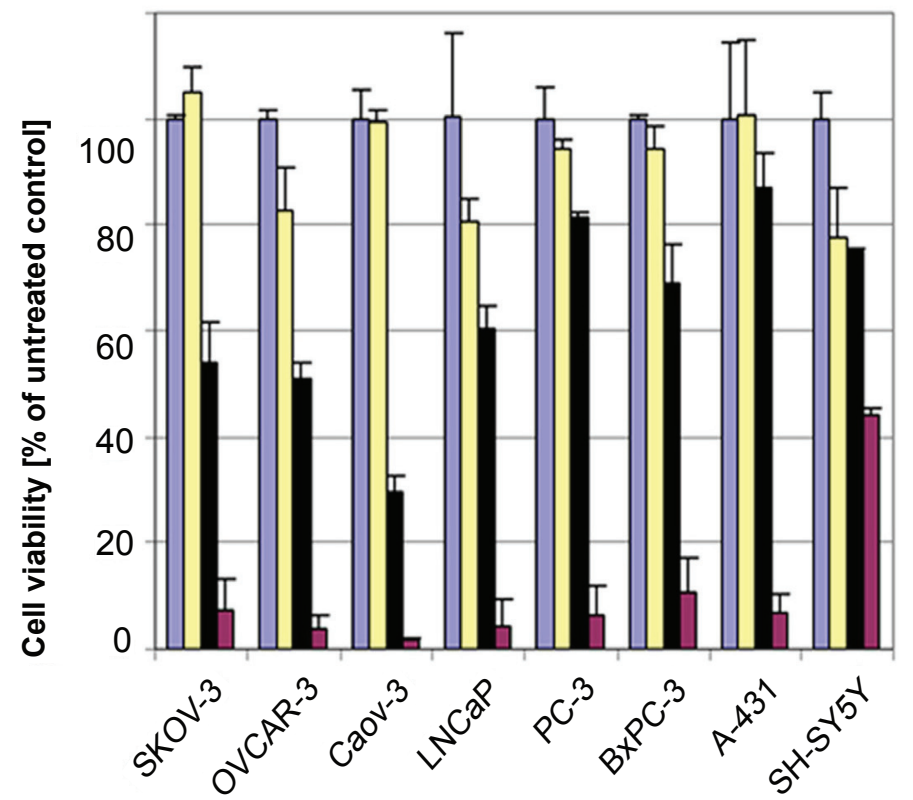

Fe-SP
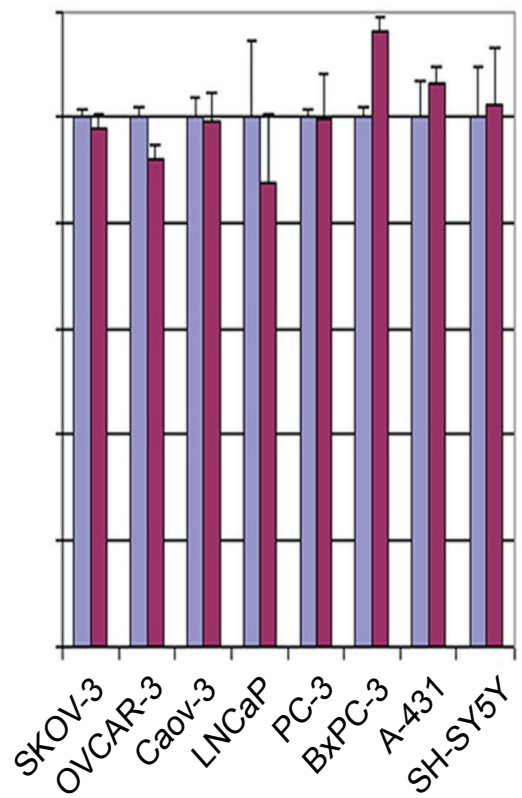

SP Ctr.

\section{$\square 0 \mu \mathrm{M} \square 0.3 \mu \mathrm{M} \square 1 \mu \mathrm{M} \square 3 \mu \mathrm{M}$}

Figure 2 Differential effect of Fe-SP on the viability of various human cancer cells. The cytotoxic effect of Fe-SP (0-3 $\mu M)$ on human ovarian cancer cells (SKOV-3, OVCAR-3, CaOV-3) was compared to various human cancer cell lines of different origin (LNCaP, PC-3, BxPC-3, A-43I, SH-SY5Y). Treatment with $3 \mu$ M SP served as a negative control. The MTS viability assay was carried out as described (Materials and methods).

Fe-SP treated cells (the majority of which, $13.4 \%$, were in late apoptotic state; Q2) while necrosis remained at background levels in control cells $(1.1 \%$, resp. $2.2 \%$, in SP-treated or nontreated cells; Figure 4B).

\section{Chemotherapeutic treatment of ovarian tumor cells with Fe-SP in an animal ovarian cancer cell model}

To evaluate the toxicity of $\mathrm{Fe}-\mathrm{SP}$ in vivo we conducted an acute toxicity study with Fe-SP applied in a single dose by intra-peritoneal (IP) injection or by PO (gavage) (Table 1). Fe-SP, at the limit dose level of $2000 \mathrm{mg} / \mathrm{kg}$ body weight PO and $5.5 \mathrm{mg} / \mathrm{kg} \mathrm{IP,} \mathrm{did} \mathrm{not} \mathrm{cause} \mathrm{any} \mathrm{mortality} \mathrm{and} \mathrm{did} \mathrm{not}$ induce any signs of toxicity in the treated female rats following dosing and during the observation period (14 days). The body weight gain of treated rats was not found to be adversely affected. Based on these results and under the conditions of this study, the median lethal dose $\left(\mathrm{LD}_{50}\right)$ of Fe-SP after single oral administration in female Fisher 344 rats was found to be (Table 1) $>2000 \mathrm{mg} / \mathrm{kg}$ by PO (left panel) and $>5.5 \mathrm{mg} / \mathrm{kg}$ body weight by IP (right panel).

To study the chemotherapeutic potential of Fe-SP in vivo an ovarian cancer model with rat ovarian NUTU-19 cancer cells injected by IP into rats was chosen. First we performed an in vitro viability assay on NUTU-19 cells which confirmed that Fe-SP but not SP lead to cell death (Figure 5A) as observed for the human ovarian cancer cell lines (SKOV-3, OVCAR-3, CaOV-3; Figure 2), though at higher concentrations. To determine the chemotherapeutic relevant doses of

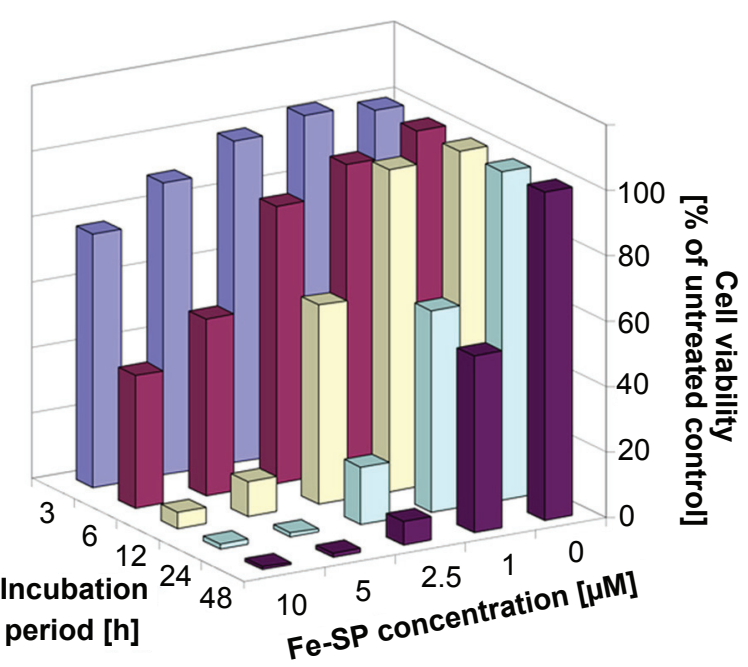

Figure 3 Kinetics of the cytotoxic effect of Fe-SP on SKOV-3 ovarian cancer cells. SKOV-3 cells were treated with various concentrations (0-10 $\mu \mathrm{M})$ of Fe-SP for 3, 6, 12, 24, or $48 \mathrm{~h}$. The MTS viability assay was carried out as described (Materials and methods). 
A
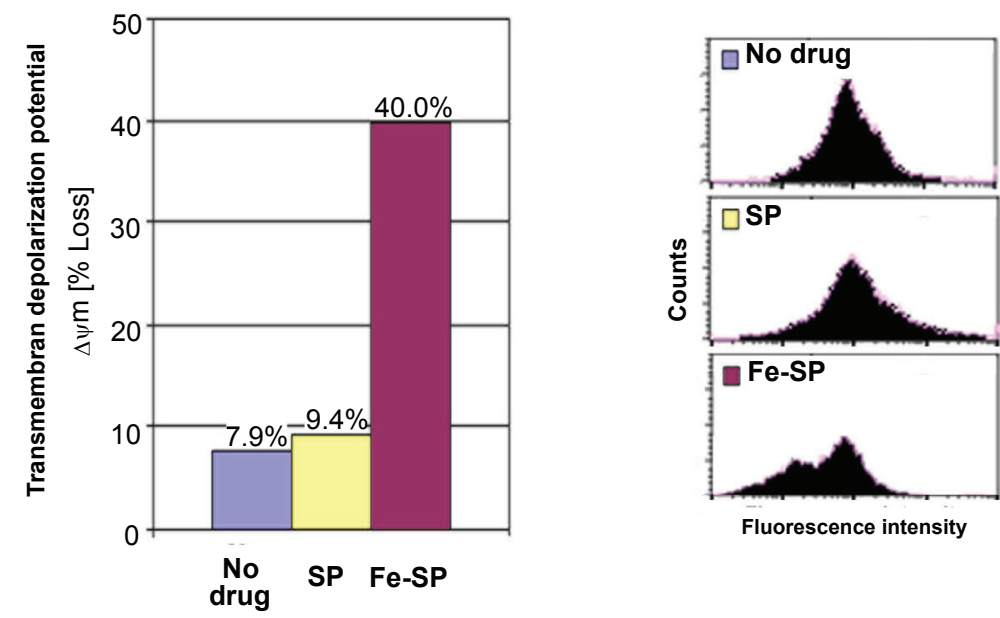

B
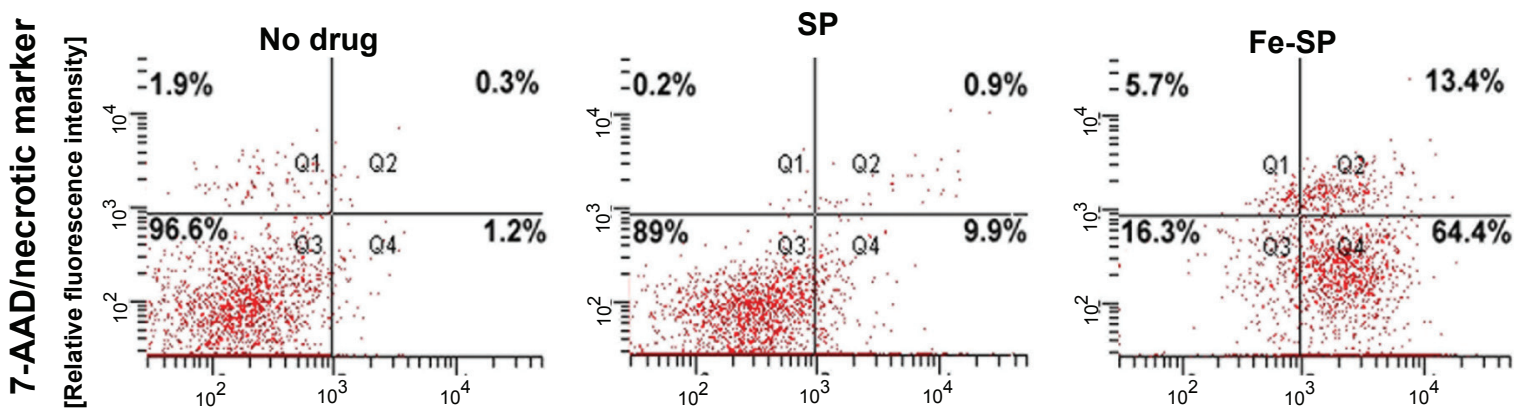

ANNEXIN V/ apoptotic marker

[Relative fluorescence intensity]

Figure 4 Determination of mitochondrial membrane depolarization, apoptotic and necrotic SKOV-3 cells after Fe-SP treatment. (A) Mitochondrial membrane depolarization analysis. SKOV-3 cells were treated for $3 \mathrm{~h}$ with $3 \mu \mathrm{M}$ Fe-SP or SP control, fixed and stained with DiOCI8(3) as described (Materials and methods). Fluorescence of the single cell population was measured by flow cytometry (right panel) and the transmembrane depolarization potential of the single cell populations plotted (bar chart, left panel). Ten thousand cells were analyzed in each sample. (B) Apoptotic and necrotic cell population. SKOV-3 cells were treated with I $\mu$ M Fe-SP or SP control for $24 \mathrm{~h}$ and floating and attached cells collected and combined. The quantification of apoptotic cells (Annexin V plasma membrane staining) and necrotic cells (7-AAD DNA staining) of SKOV-3 cells was carried out by flow cytometry as described (see Materials and methods). Ten thousand events were analyzed for each sample.

Fe-SP NUTU-19 cells were injected and three weeks after development of tumors (to mimic the situation following cytoreductive surgery) animals were either left untreated (10 animals) or treated daily with Fe-SP $(0.5$ or $1 \mathrm{mg} / \mathrm{kg}$ body weight, five animals in each group) via IP. Duration of treatment lasted 12 days and was based on tumor burden in the control animals. Western blotting confirmed activation of effector caspase-3 and inactivation of PARP-1 (involved in DNA repair) in tumor tissue after Fe-SP treatment ( 0.5 and $1 \mathrm{mg} / \mathrm{kg}$ body weight) of the animals but not in tumor tissue of untreated animals (Figure 5B). This directly mirrors the induction of apoptosis observed in human ovarian cancer cells in vitro. ${ }^{14}$ Control animals showed a consistently elevated amount of hemorrhagic ascites. In contrast, treated animals displayed significantly less hemorrhagic ascites volume (Figure 5C) with a response in 70\% (7 of 10) of animals treated: $40 \%$ of animals (one in the $0.5 \mathrm{mg} / \mathrm{kg}$ group and three in the $1.0 \mathrm{mg} / \mathrm{kg}$ group) displayed a complete response with no residual hemorrhagic ascites and no visible tumor (Figure 5D, example image shown). An additional 30\% of animals treated (two in the $0.5 \mathrm{mg} / \mathrm{kg}$ group and one in the $1.0 \mathrm{mg} / \mathrm{kg}$ group) displayed a partial response. In addition, omental weight in the Fe-SP treatment group was consistently decreased in Fe-SP-treated animals versus nontreated controls (Figure 5C).

\section{Discussion}

A low survival rate for woman suffering from ovarian cancer is related to the development of resistance of tumor cells to standard platinum-derived chemotherapeutic agents and therefore new anti-cancer drugs need to be developed. . $^{2,4}$ Transition metal salophene complexes are candidate agents for treatment of ovarian cancer. ${ }^{14}$

To compare the cytotoxicity of Fe(III)-salophene, $\mathrm{Co}(\mathrm{III})-, \mathrm{Mn}(\mathrm{II})-$, and $\mathrm{Co}(\mathrm{II})$-salophene (-SP) we chose two ovarian adenocarcinoma cell lines (OVCAR-3; SKOV-3) 
Table I Acute toxicity of iron salophene

\begin{tabular}{|c|c|c|c|c|c|c|c|}
\hline \multicolumn{4}{|c|}{$\begin{array}{l}\text { PO administration Up and Down Method (UDM) as per OECD } \\
\text { guideline } 425\end{array}$} & \multicolumn{4}{|c|}{$\begin{array}{l}\text { IP administration Up and Down Method (UDM) as per } \\
\text { OECD guideline } 425\end{array}$} \\
\hline Animal \# & Dose (mg/kg) & Outcome & $\mathbf{L D}_{50}(\mathrm{PO})$ & Animal \# & Dose (mg/kg) & Outcome & $\mathbf{L D}_{50}(\mathrm{IP})$ \\
\hline $\mathrm{I}$ & 55 & 0 & & 1 & 17.5 & $\mathrm{X}$ & \\
\hline 2 & 175 & 0 & & 2 & 5.5 & O & \\
\hline 3 & 550 & 0 & & 3 & 17.5 & $x$ & $>5.5 \mathrm{mg} / \mathrm{Kg}$ \\
\hline 4 & 2000 & 0 & $>2000 \mathrm{mg} / \mathrm{Kg}$ & 4 & 5.5 & 0 & \\
\hline 5 & 2000 & 0 & & 5 & 17.5 & $x$ & \\
\hline 6 & 2000 & 0 & & 6 & 5.5 & 0 & \\
\hline 7 & 2000 & 0 & & & & & \\
\hline
\end{tabular}

Notes: O, No Response; X, Death within 2-14 days.

that are multi-drug resistant (see http://www.atcc.org). For a subsequent study of the selective cytotoxicity of the most effective salophene complex (Fe-SP) within a panel of cell lines of different tumor origin we added a third ovarian adenocarcinoma cell line $\left(\mathrm{CaOV}-3\right.$, resistant to cisplatin ${ }^{19}$, two human adenocarcinoma cell lines (PC-3/prostate tumor; $\mathrm{BxPC}-3$ /pancreatic tumor) and an epidermoid skin carcinoma line (A-431); a prostate carcinoma line (LNCaP) and a neuroblastoma line (SH-SY5Y). Previously, we showed that Fe-SP at $1 \mu \mathrm{M}$ caused selective cytotoxicity and apoptosis in SKOV-3 cells when compared to primary fibroblasts which did not show altered growth or morphology at this concentration of Fe-SP. ${ }^{14}$ In contrast to fibroblasts, all the nonovarian cell lines studied here responded to Fe-SP at $1 \mu \mathrm{M}$. However, it was apparent that their viability was less affected than of all three ovarian cancer cell lines tested here indicating a dose-dependent and selective cytotoxicity of Fe-SP with ovarian cancer cells being more sensitive to treatment in vitro. More importantly, our trial study in an animal ovarian cancer model suggested that tumors in rats derived from ovarian cancer cells recede upon Fe-SP treatment, while no systemic toxicity in treated animals was detected.

The present state of research in the field of organometallic compounds such as salophenes or salens (related compound, see introduction) allows us to only speculate on the possible mechanism(s) of cytotoxic action of Fe-SP in cancer cells. A remarkable feature of metallo-salens, not yet analyzed for salophenes, is their affinity to a variety of aromatic neutral molecules; ${ }^{20,21}$ salens when complexed with transition metals act as artificial nucleases. Their reactivity in plasmid DNA cleavage assays can be controlled by conjugation or by the type and charge of the central metal ion core. ${ }^{22,23}$ For example, $\mathrm{Ni}(\mathrm{II})$ - or $\mathrm{Mn}(\mathrm{II})$-salens were found to efficiently induce DNA strand scission ${ }^{22,24}$ but not of Fe(II)-salens unless hydroxyl groups facilitate their oxidation to Fe(III) species. ${ }^{23}$ Accordingly, in the present report we observed a high cytotoxicity and induction of apoptosis by the Fe(III)-SP complex. However, the cytotoxicity of Mn(III)-SP observed here was not complex-specific but similar to treatment with the respective chloride-salt. Thus, for Mn-SP, involvement of DNA cleavage mechanisms did not appear to be essential in cell death of SKOV-3 or OVCAR-3. It has been postulated that Fe-salen in cooperation with the quinine system facilitates the formation of iron(III) $\mathrm{O}_{2}{ }^{-}$species to produce free hydroxy radicals responsible for DNA cleavage. ${ }^{25}$ The DNA cleavage activity of $\mathrm{Fe}(\mathrm{III})$-salen is partially linked to high water-solubility and charge ${ }^{24}$ which also likely applies to Fe(III)-SP. The cytotoxicity observed for Fe(III)-SP may follow the same mechanism known for Fe(III)-salen (similar charge mainly due to the metal-core). However, cell death induced by Fe-SP occurs with a 15-50-fold (depending on the cell line used) higher efficiency (Figure 2). ${ }^{14,24}$ In all three studies the same viability assay was employed.

Our previous data ${ }^{14}$ suggested that Fe-SP treatment affected cell-cycle checkpoints of SKOV-3 cells in S-phase. Targeting cell cycle checkpoints has been proposed as an alternative approach to anti-cancer therapies. ${ }^{26-28}$ While the mechanism of the cytotoxic effect of salens or Fe-SP on cells in culture or in vivo remains to be investigated, selective induction of apoptosis after drug treatment in vitro is a first indicator for potential effects on tumor metastasis and cell physiology in vivo. Fe-SP caused apoptosis in SKOV-3 cells ${ }^{14}$ and in vivo (present study). Within $3 \mathrm{~h}$ of Fe-SP treatment we observed a loss of mitochondrial transmembrane depolarization potential $(\Delta \Psi \mathrm{m})$ in SKOV-3 cells. The loss of $\Delta \Psi \mathrm{m}$ due to chemical agents for other drug-treated cell 
A

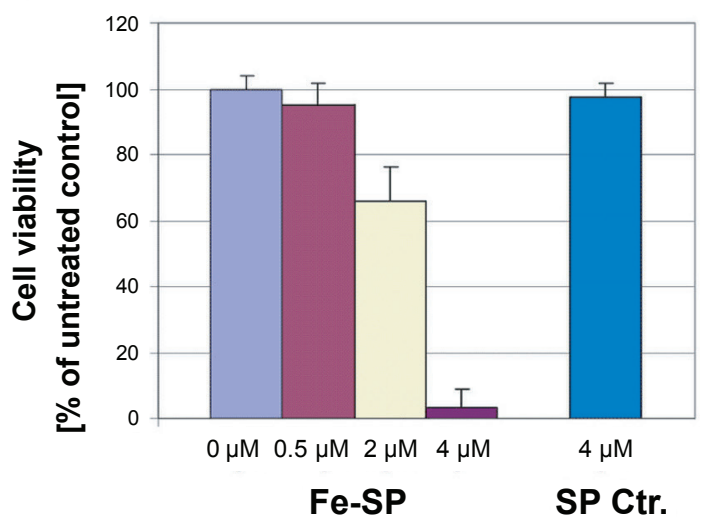

B

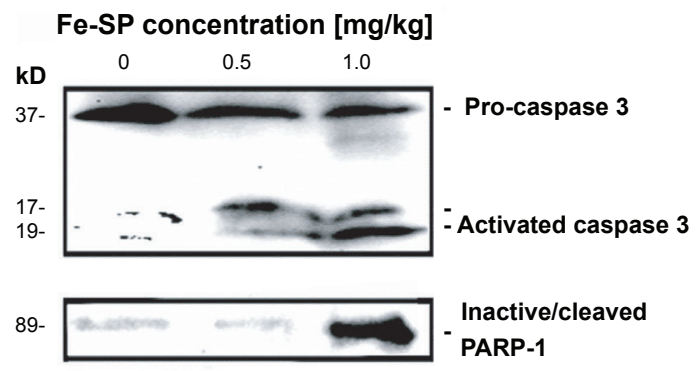

C
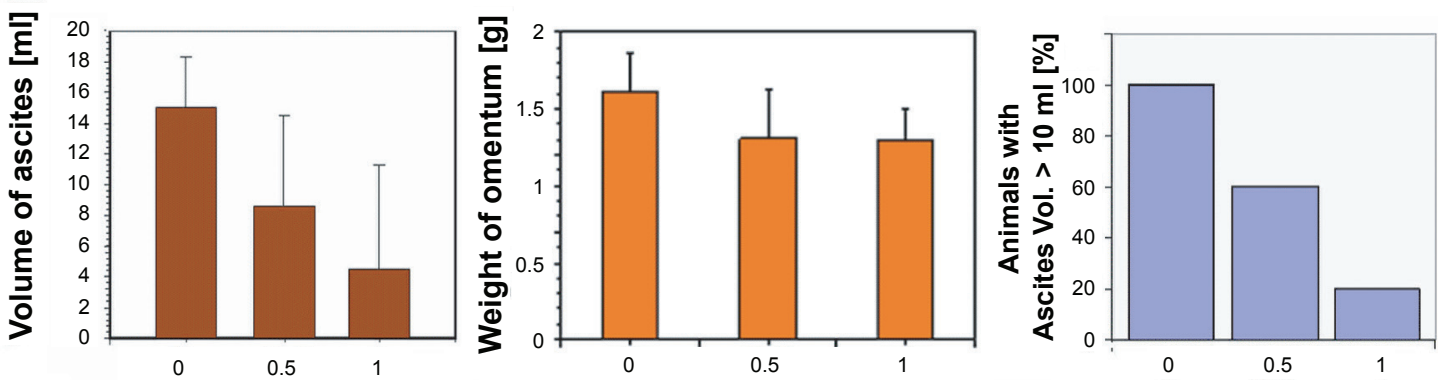

\section{Concentration [mg/kg]}

D

Fe-SP treated [1 $\mathrm{mg} / \mathrm{kg}]$

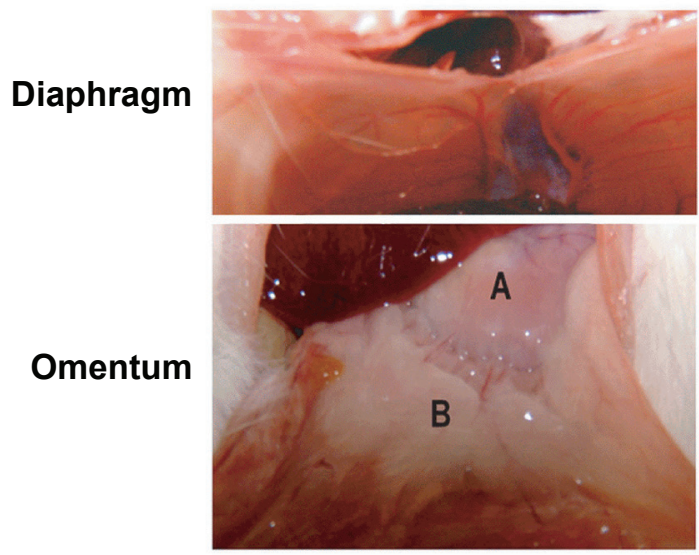

Untreated
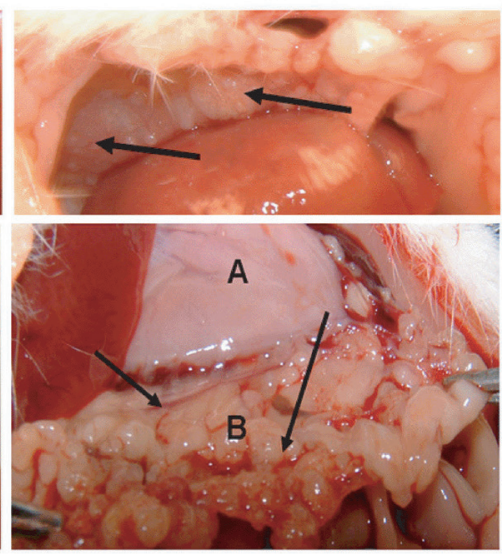

Figure 5 Chemotherapeutic effect of Fe-SP in an animal ovarian cancer cell model. (A) Effect of Fe-SP on the viability of rat ovarian cancer cells (NUTU-I9) in vitro. Rat ovarian cancer cells (NUTU-19) were plated into 96 well flat bottom plates and treated with various concentrations $(0.5-4 \mu M)$ of Fe-SP or $4 \mu M$ noncomplexed SP.The MTS viability assay was carried out as described (Materials and Methods). (B) In vivo activation of Caspase-3 and in-activation of PARP-I in ovarian cancer cell-derived tumors after Fe-SP treatment. NUTU- 19 derived tumor tissue of nontreated or Fe-SP treated ( $0.5 \mathrm{mg} / \mathrm{kg}$ or $1.0 \mathrm{mg} / \mathrm{kg}$ bodyweight) rats was pooled for each treatment group. Cell lysates were prepared in the presence of a broad range of proteinase inhibitors to prevent protein degradation and the expression of caspase-3 and PARP-I was analyzed by immunoblotting (see Material and methods). Cell lysates $50 \mu \mathrm{g}$ of total cellular protein/lane were separated on a I2\% SDS-polyacrylamide gel. PARP-I was visualized using a primary antibody solely recognizing the inactivated/cleaved protein. For caspase- 3 an antibody which recognizes the full length pro-form as well as activated/cleaved fragments of the protein was used. Thus, a direct conversion of the precursor into activated caspase-3 was monitored for all samples allowing direct comparison of loading between samples from treated and nontreated animals. (C) Volume of ascites and weight of omentum from Fe-SP treated rats with SKOV-3 derived tumors. Graphs show a trend for decreased ascites and omental tumor burden after Fe-SP $(0.5,1.0 \mathrm{mg} / \mathrm{kg}$ ) treatment. (D) Image of diaphragm and omentum. Example of complete response of a SKOV-3 derived tumor to Fe-SP at concentration of I mg/kg body weight. Following treatment both the diaphragm and omentum are disease free. 
types has been reported to be indicator of early apoptosis and as the first irreversible step in the induction of apoptosis. ${ }^{29,30}$ Accordingly, loss of the $\Delta \Psi \mathrm{m}$ within $3 \mathrm{~h}$ in SKOV-3 following Fe-SP treatment as seen here may be the first irreversible apoptotic event triggered by this agent. Previously, induction of apoptosis was shown to contribute to cell death of hEK293 (human kidney cells) upon Fe(III)-salen treatment. ${ }^{24}$ To date, no further studies to the morphology and apoptotic signaling of any cell lines after treatment with compounds falling into the class of iron-salens or -salophenes have been published.

To set the stage for further investigation of Fe-SP as a potential therapeutic drug in addition to these in vitro studies we conducted a study on the systemic toxicity of Fe-SP when applied in rats as a model system. When applied in rats Fe-SP neither revealed acute toxicity (at concentrations $\leq 5.5 \mathrm{mg} / \mathrm{kg}$ for IP administration, $\leq 2000 \mathrm{mg} / \mathrm{kg}$ for oral administration; present study) nor systemic toxicity (at concentrations $\leq 4 \mathrm{mg} / \mathrm{kg}^{14}$ ) that all exceeded the chemotherapeutic relevant doses $(\leq 1 \mathrm{mg} / \mathrm{kg}$ body weight) of Fe-SP determined in the study trial presented here in a rat ovarian cancer cell model. In tumors of Fe-SP treated animals, but not in tumors of untreated rats, apoptotic events, such as caspase-3 activation and PARP deactivation occurred. The present report suggests that Fe-SP is a potent growth-suppressing agent in vitro for cell lines derived from ovarian cancer and a potential therapeutic drug to treat such tumors in vivo.

\section{Disclosure}

The authors declare no conflicts of interest in this work.

\section{References}

1. Heintz APM, Odicino F, Maisonneuve P, Beller U, Benedet JL, Creasman WT. International Federation of Gynecology and Obstetrics 25th Annual Report. Carcinoma of the Ovary. Int J Gyn Obst. 2003;83:135-137.

2. American Cancer Society. Cancer facts and figures. 2007. Cited on Nov 6, 2008. Available from http://www.cancer.org.

3. McGuire WP, Hoskins WJ, Brady MF, et al. Cyclophosphamide and cisplatin compared with paclitaxel and cisplatin in patients with stage III and stage IV ovarian cancer. N Engl J Med. 1996;334:1-6.

4. McGuire WP, Ozols RF. Chemotherapy of advanced ovarian cancer. Semin Oncol. 1998;25:340-348.

5. Piccart MJ, Bertelsen K, James K, et al. Randomized intergroup trial of cisplatin-paclitaxel versus cisplatin-cyclophosphamide in women with advanced epithelial ovarian cancer: three-year results. J Natl Cancer Inst. 2000;92:699-708.

6. Leitao MM Jr, Hummer A, Dizon DS, et al. Platinum re-treatment of platinum-resistant ovarian cancer after non-platinum therapy. Gynecol Oncol. 2003;91:123-129.

7. Lamberth E, Gregory WM, Nelstrop AE, Rustin GJ. Long-term survival in 463 women treated with platinum analogs for advanced epithelial carcinoma of the ovary: life expectancy compared to women of an agematched normal population. Int J Gynecol Cancer. 2004;14:772-778.
8. Ott I, Gust R. Non platinum metal complexes as anti-cancer drugs. Arch Pharm. 2007;340:117-126.

9. Andrews P, Howell S. Cellular pharmacology of cisplatin: perspectives on mechanisms of acquired resistance. Cancer Cell. 1990;2:35-43.

10. Horowitz N, Hua J, Gibb R, Mutch D, Herzog T. The role of topotecan for extending the platinum-free interval in recurrent ovarian cancer: an in vitro model. Gynecol Oncol. 2004;94:67-73.

11. Köpf-Maier P. Complexes of metals other than platinum as antitumour agents. Eur J Clin Pharmacol. 1994;47:1-16.

12. Huang R, Wallquist A, Covell DG. Anticancer metal compounds in NCI-s tumor-screening database: putative mode of action. Biochem Pharmacol. 2005;69:1009-1039.

13. Zhong X, Weih, Liu WS, Wang DQ, Wang X. The crystal structures of copper(II), manganese(II), and nickel(II) complexes of a (Z)-2-hydroxyN'-(2-oxoindolin-3-ylidene) benzohydrazide-potential antitumor agents. Bioorg Med Chem Lett. 2007;17:3774-3777.

14. Lange TS, Kim KK, Singh RK, Strongin RM, McCourt CK, Brard L. Iron(III)-salophene: An metallo-organic compound with selective cytotoxic and anti-proliferative properties in platinum-resistant ovarian cancer cells. PLOS One. 2008;3(e2303):1-10.

15. Bi C, Fan Y, Sun G, Zheng G, Zhang G. Synthesis and characterization of Ln(III) complexes with N,N'-p-phenylenebis-(o-vanillylideneimine). Syn React Inorg Met. 2001;31:219-225.

16. Rose GS, Tocco LM, Granger GA, et al. Development and characterization of a clinically useful animal model of epithelial ovarian cancer in the Fischer 344 rat. Am J Obstet Gynecol. 1996;175:593-599.

17. Lange TS, Singh RK, Kim KK, et al. Anti-proliferative and pro-apoptotic Properties of 3-Bromoacetoxy Calcidiol (B3CD) in high-Risk Neuroblastoma. Chem Biol Drug Design. 2007;70:302-310.

18. Malich G, Markovic B, Winder C. The sensitivity and specificity of the MTS tetrazolium assay for detecting the in vitro cytotoxicity of 20 chemicals using human cell lines. Toxicology. 1997;124:179-192.

19. Hayakawa J, Ohmichi M, Kurachi H, et al. Inhibition of extracellular signal-regulated protein kinase or c-Jun N-terminal protein kinase cascade, differentially activated by cisplatin, sensitizes human ovarian cancer cell line. J Biol Chem. 1999;274:31648-31654.

20. Burrows CJ, Rokita SE. Recognition of guanine structure in nucleic acids by nickel complexes. Acc Chem Res. 1994;27:295-301.

21. Mandal SS, Varshney U, Bhattacharya S. Role of the central metal ion and ligand charge in the DNA binding and modification by metallosalen complexes. Bioconjugate Chem. 1997;8:798-812.

22. Routier S, Cotelle N, Catteau JP, et al. Salen-anthraquinone conjugates. Synthesis, DNA-binding and cleaving properties, effects on topoisomerases and cytotoxicity. Bioorg Med Chem. 1996;4:1185-1196.

23. Routier S, Bernier JL, Catteau JP, et al. Synthesis, DNA binding, and cleaving properties of an ellipticine-salen.copper conjugate. Bioconjugate Chem. 1997;8:789-792.

24. Woldemariam GA, Mandal SS. Iron(III)-salen damages DNA and induces apoptosis inhuman cells via mitochondrial pathway. J Inorg Biochem. 2008;102:740-747.

25. Routier, S Vezinh, Lamour E, Bernier JL, Catteau JP, Bailly C. DNAcleavage by hydroxy-salicylidene-ethylendiamine-iron complexes. $\mathrm{Nucl}$ Acid Res. 1999;27:4160-4166.

26. Shapiro GI, Harper JW. Anticancer drug targets: cell-cycle and checkpoint control. J Clin Invest. 1999;104:1645-1653.

27. Gladden AB, Diehl JA. Cell-cycle progression without cyclin E/CDK2: breaking down the walls of dogma. Cancer Cell. 2003;4:160-162.

28. Mazumder S, DuPree EL, Almasan A. A dual role of cyclin E in cell proliferation and apoptosis may provide a target for cancer therapy. Curr Cancer Drug Targets. 2004;4:65-75.

29. Kim R, Emi M, Tanabe K, Murakami S, Uchida Y, Arihiro K. Regulation and interplay of apoptotic and non-apoptotic cell death. J Pathol. 2006;208:319-326.

30. Petit PX, Lecoeur H, Zorn E, Dauguet C, Mignotte B, Gougeon ML. Alterations in mitochondrial structure and function are early events of dexamethasone-induced thymocyte apoptosis. J Cell Biol. 1995;130:157-167. 